\title{
Critical Current Measurements of the Main LHC Superconducting Cables
}

\author{
A. P. Verweij and A. K. Ghosh
}

\begin{abstract}
For the main dipole and quadrupole magnets of the LHC, CERN has ordered from industry about $7000 \mathrm{~km}$ of superconducting Nb-Ti Rutherford type cables, delivered between 1999 and 2005. The strands of these cables are produced by six different companies, and cabled on five different machines. In the framework of the US contribution to the LHC, BNL has been testing and analyzing the electrical properties of samples of these cables. The main purpose of these tests was to qualify the critical current of the entire cable production in the frame of the quality assurance program implemented by CERN to assure the overall strand and cable performances.

In total more than 2100 cable samples have been evaluated at $4.3 \mathrm{~K}$ in terms of critical current $I_{\mathrm{C}}$, n-value and the residual resistance ratio, RRR. This paper will present an overview of the results, and show the correlations of the critical current and n-value between virgin strands, extracted strands, and cables. Also described are correlations of $I_{\mathrm{C}}$ measured at BNL and those made at the FRESCA facility in CERN. Furthermore a few trends and anomalies of the cable production that were detected from testing cables are highlighted.
\end{abstract}

Index Terms-Critical current, large hadron collider, quench current, superconducting cables, superconducting magnets.

\section{INTRODUCTION}

$\mathbf{T}$ THE Large Hadron Collider (LHC) currently under construction at CERN required the fabrication and validation of $7350 \mathrm{~km}$ of $\mathrm{Nb}$-Ti superconducting cable [1], of which 7000 $\mathrm{km}$ were for the main dipole and quadrupole magnets. The 1232 main dipoles have two layers of keystoned Rutherford cables, called cable type 01 and 02 respectively. Four unit lengths (UL) of cable type 01 (each $450 \mathrm{~m}$ long) and four UL of type 02 (each $740 \mathrm{~m}$ long) are used to wind the four poles of the two apertures of a dipole magnet. The 392 main quadrupole magnets require each two lengths of $660 \mathrm{~m}$ of cable type 03 , having the same specifications as cable type 02 . The main characteristics of these cables are given in Table I. An extensive R\&D program started in 1988 focused on cable geometry, critical current, inter-strand cross contact resistance, magnetization and stability. R\&D contracts were placed with several European companies in the years 1988-1994, followed by prequalification contracts in 1995-1996. Finally, contracts were awarded to six companies, and were signed at the end of 1998. A review of the R\&D and supply of these cables can be found in [2], [3].

Manuscript received August 28, 2006. The work at BNL was supported by the U.S. Department of Energy under Contract No. DE-AC02-98CH108865.

A. P. Verweij is with the European Laboratory for Particle Physics, CERN, CH-1211 Geneva 23, Switzerland (e-mail: Arjan.Verweij@cern.ch).

A. K. Ghosh is with Brookhaven National Laboratory, Upton, NY 11973 USA.

Digital Object Identifier 10.1109/TASC.2007.898000
TABLE I

MAIN CABLE AND STRAND CHARACTERISTICS

\begin{tabular}{llll}
\hline \hline & Cable 01 & Cable 02 & \multicolumn{1}{c}{ Cable 03 } \\
\hline Delivered no of UL & 5369 & 5407 & 894 \\
Length of a UL & $450 \mathrm{~m}$ & $740 \mathrm{~m}$ & $660 \mathrm{~m}$ \\
Cable & & & \\
$\quad$ Width & $15.08-15.10 \mathrm{~mm}$ & $15.08-15.10 \mathrm{~mm}$ \\
$\quad$ Thin edge & $1.736 \pm 0.006 \mathrm{~mm}$ & $1.462 \pm 0.006 \mathrm{~mm}$ \\
$\quad$ Thick edge & $2.064 \pm 0.006 \mathrm{~mm}$ & $1.598 \pm 0.006 \mathrm{~mm}$ \\
$\quad$ Mid thickness & $1.900 \pm 0.006 \mathrm{~mm}$ & $1.480 \pm 0.006 \mathrm{~mm}$ \\
$\quad$ Number of strands & 28 & 36 \\
Transposition pitch & $110 \pm 5 \mathrm{~mm}$ & $100 \pm 5 \mathrm{~mm}$ \\
$\quad$ Cable Ic @ 4.222K, 7 T & $>14140 \mathrm{~A}$ & \\
$\quad$ Cable Ic@ $4.222 \mathrm{~K}, 6 \mathrm{~T}$ & & $>13236 \mathrm{~A}$ \\
$\quad$ Cable Ic @ 1.900 K, 10 T & $>13750 \mathrm{~A}$ & \\
$\quad$ Cable Ic @ 1.900 K, 9 T & & $>12960 \mathrm{~A}$ \\
Strand & & \\
$\quad$ Diameter & $1.0650 \pm 0.0025 \mathrm{~mm}$ & $0.8250 \pm 0.0025 \mathrm{~mm}$ \\
$\quad$ Cu/SC ratio & $1.6-1.7$ & $1.9-2.0$ \\
$\quad$ Strand Ic @ 1.900 K, 10 T & $>515 \mathrm{~A}$ & $>380 \mathrm{~A}$ \\
$\quad$ Strand Ic @ 1.900 K, 9 T & & \\
\hline \hline
\end{tabular}

Already in the R\&D phase a collaboration with BNL was set-up to measure the critical current $\left(I_{\mathrm{C}_{-} \text {cab }}\right)$ of short samples of cables. Before the year 2000 a few hundred samples had been measured and evaluated by BNL, using the same test facility used earlier for qualification of the RHIC conductor. In 1998 an official agreement was signed between CERN and BNL, in the framework of the US collaboration to the LHC, for the testing of a few thousand cables samples at $4.2 \mathrm{~K}$ over a six year period. The main purpose of these tests was to qualify the cable critical current at $4.2 \mathrm{~K}$ during the entire cable production, and to provide feedback to CERN and the contractors in case of non-uniformities or anomalies. This large test program required an upgrade of the BNL test facility from one to three cryostats. In parallel, at CERN a new test facility (called FRESCA) was built during the years 1995-1998 [4]. The main purpose of FRESCA was to verify the $1.9-4.2 \mathrm{~K}$ correlation during LHC production, and to investigate in detail any suspicious cable. Furthermore, the facility was designed to perform additional R\&D related to cable stability, ramp rate sensitivity, cable-to-cable joint, field direction, etc.

Characteristics of the test facilities at BNL and CERN will be given in Section II, as well as the test protocols used, and the qualification of the test facilities using a reference cable.

In total we measured 2131 samples, of which 1980 at BNL and 151 at FRESCA, see Fig. 1. On average this corresponds to one sample for each $5.5 \mathrm{UL}$, or one sample per $3.3 \mathrm{~km}$ of cable. However, we varied the sampling rates considerably during the seven years of cable production, with a relatively high rate at the 


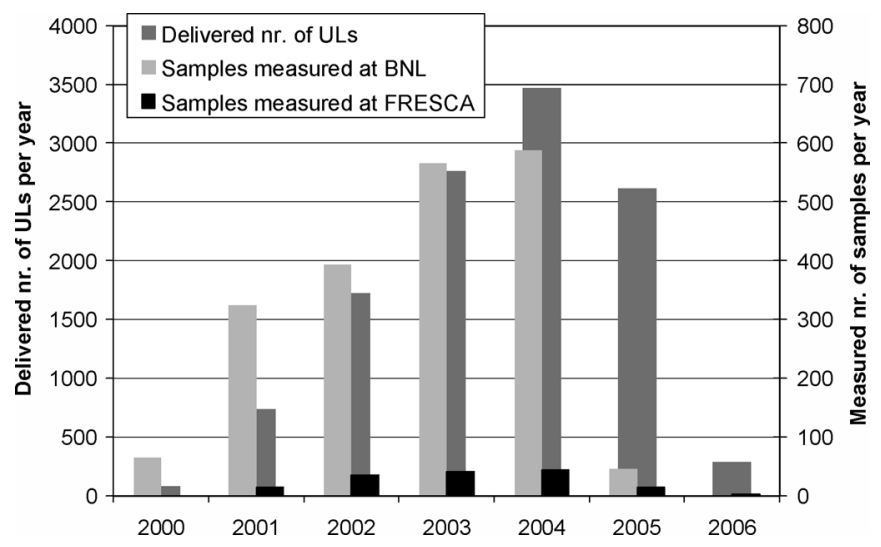

Fig. 1. Cable delivery (left axis) and measured cable samples (right axis) at BNL and FRESCA during the seven years of cable production.

start of production in order to better evaluate the initial product and give feedback to the contractors.

Note that the contract with BNL ended in spring 2005 resulting in a very limited number of samples in 2005. We qualified the last years of cable production mainly by extracted strand measurements in combination with a limited number of cable measurements in FRESCA, see also Section III-C.

As mentioned before, the strands have been produced by six different contractors that performed the cabling in-house or at a subcontractor. The list of cable codes is given in Table II, showing the contractor, cabling company, delivered number of UL, and measured number of samples. Note that the cabling codes starting with 02 also include the cable types 03. Cabling at Alstom, FEC, and NEEWC was performed on one cabling machine, whereas cabling at Brugg was done on two different machines. Note also that Alstom and EM/OCSI subcontracted part of the cabling of the $02 \mathrm{~B}$ and $02 \mathrm{C}$ cables to FEC in order to benefit from the cabling capacity at FEC and hence increase delivery rates. $I_{\text {C_cab }}$ sampling rates for each manufacturer were set according to the quality of previously delivered cables from that manufacturer, and available measurement capacity.

An overview of the test results is given in Section III. Some results on anomalies observed during cable testing will be given in Section IV.

\section{Description OF THE Test FACILITIES}

\section{A. BNL Test Facilities}

BNL has three test stations (denoted as TB-4, TB-5, and TB-6) that are run sequentially, that means that one station is cooling down, one is warming up and one is under test. A maximum of 20 samples per week can be tested. Two pairs of bare cable samples, each in a bifilar arrangement, are configured as a stack and electrically connected in series after having been insulated by means of G10 and Mylar strips. The stack is then mounted in the sample holder at a pressure of $70 \mathrm{MPa}$, applied perpendicular to the cable face. With this method the training behavior is limited to a few quenches. The background field for the test is provided by a $7 \mathrm{~T}$ dipole magnet with a uniform field over a length of $60 \mathrm{~cm}$. The current in the cable samples
TABLE II

Number of CABle $I_{c}$ Measurements Per CABle Producer

\begin{tabular}{llllll}
\hline \hline $\begin{array}{l}\text { Cable } \\
\text { code }\end{array}$ & Contractor & $\begin{array}{l}\text { Cabling } \\
\text { company }\end{array}$ & $\begin{array}{l}\text { Delivered } \\
\text { no of ULs }\end{array}$ & $\begin{array}{l}\text { No of Ic meas. } \\
\text { @BNL }\end{array}$ & @FESCA \\
\hline 01B & Alstom & Alstom & 3400 & 452 & 48 \\
01E & VAC/EAS & Brugg & 1969 & 224 & 24 \\
02B & Alstom & Alstom \& FEC & 2463 & 426 & 26 \\
02C & EM/OCSI & Brugg \& FEC & 1423 & 295 & 17 \\
02D & OKSC & NEEWC & 770 & 135 & 7 \\
02G & IGC/OKAS & FEC & 829 & 216 & 17 \\
02K & FEC & FEC & 816 & 232 & 12 \\
Total & & & $\mathbf{1 1 6 7 0}$ & $\mathbf{1 9 8 0}$ & $\mathbf{1 5 1}$ \\
\hline \hline
\end{tabular}

Alstom: Alstom Magnets and Superconductors, France

Brugg: Brugg Cables, Switzerland

EAS: European Advanced Superconductors (formerly VAC), Germany

EM: Europa Metalli, Italy (now OCSI)

FEC: Furukawa Electric Company, Japan

IGC: Intermagnetics General Corporation, USA (now OKAS)

NEEWC: New England Electric Wire Corporation, USA

OCSI: Outokumpu Copper Superconductors Italy (formerly EM), Italy

OKAS: Outokumpu Advanced Superconductors (formerly IGC), USA

OKSC: Outokumpu Superconductors, Finland

VAC: Vacuumschmelze, Germany (now EAS)

is supplied by an external $25 \mathrm{kA}$ power supply. All tests are performed at about $4.4 \mathrm{~K}$. More details about the BNL test stations can be found in [5], [6].

\section{B. CERN Test Facility (FRESCA)}

FRESCA is based on the same measurement configuration as the BNL test stations, namely a bifilar cable sample placed in a dipolar field. The main differences are the higher background field of FRESCA (10 T), and the fact that all measurements in FRESCA are not only done at $4.4 \mathrm{~K}$ but also at $1.9 \mathrm{~K}$. Furthermore, the sample current is also higher (maximum $32 \mathrm{kA}$ ), and supplied by a very low noise power supply, enabling very accurate voltage measurements with accuracies better than $0.1 \mu \mathrm{V}$. The sample holder comprises only two samples, and the measurement rate is limited to four samples per week. The samples are compressed with $80 \mathrm{MPa}$, and the voltage is registered over a length of $60 \mathrm{~cm}$. An array of Hall probes is located next to each cable sample to verify the uniformity of the transport current among the strands during test. More details about the test facility and the background magnet can be found in [4] and [7] respectively.

\section{Measurement Procedure}

At a given applied field BA, field direction, and helium bath temperature the Voltage Current $(U I)$ curve is measured at constant current ramp rate (typically $100-200 \mathrm{~A} / \mathrm{s}$ ), starting at $0 \mathrm{~A}$ until quench. The current $I$, voltage $U$ and temperature $T$ during the ramp are recorded with a sampling frequency of about $10 \mathrm{~Hz}$.

The measured critical current $I_{\mathrm{M}}$ and the quality index $n$ are then obtained by fitting the measured points to:

$$
U(I)=U_{\text {off }}+R_{\text {slope }} I+U_{C} \cdot\left(\frac{I}{I_{M}}\right)^{n}
$$




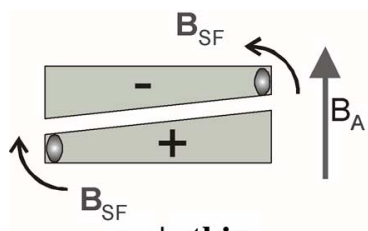

a. $\perp$-thin

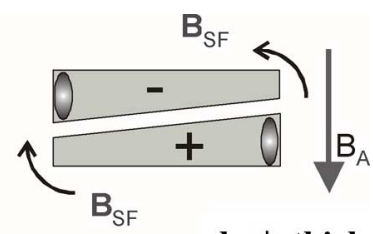

b. $\perp$-thick
Fig. 2. Schematic cross-section of the bifilar sample configuration showing the peak field location at the (a) thin and (b) thick edges of the samples.

with:

$$
\begin{aligned}
& U_{\text {off }} \quad \begin{array}{l}
\text { the offset voltage caused by the measurement } \\
\text { instrument and the inductive part during the } \\
\text { constant current increase. }
\end{array} \\
& R_{\text {slope }} \quad \begin{array}{l}
\text { dynamic resistance related to the transport current } \\
\text { penetration, see also [8] }
\end{array} \\
& U_{\mathrm{C}} \quad \begin{array}{l}
\text { the critical voltage at } I=I_{\mathrm{M}} \text { equal to: }
\end{array}
\end{aligned}
$$

$$
U_{C}=10^{-14} \frac{l}{N_{s} \pi\left(d_{s}^{2} / 4\right)} I_{M}
$$

with $N_{\mathrm{s}}$ the number of strands in the cable, $l$ the distance between the voltage taps, and $d_{\mathrm{S}}$ the strand diameter. Note that $R_{\text {slope }} I$ is much smaller than $U_{\mathrm{C}}$ and contributes therefore only a minor part to the total voltage.

Qualification of the cable is done with the field oriented perpendicular to the cable face, so as to have the peak field at the thin edge of the cable, i.e. the edge which is most deformed and hence prone to the largest $I_{\mathrm{C}}$ degradation [see Fig. (2a)]. The configuration with the peak field on the thick edge [see Fig. (2b)] is also measured in FRESCA and in about $10 \%$ of the cases at $\mathrm{BNL}$. The above given configurations are denoted as $\perp$-thin and $\perp$-thick. Configurations with the field parallel to the cable width are not discussed in this paper.

The magnetic field is the sum of the applied field and the selffield BSF, where the latter varies significantly over the crosssection of the cable. In order to better compare $I_{\mathrm{C} \_c a b}$ with the strand critical current $I_{\text {C_str }}$, the field taken into consideration is the average total field of that strand in the cable which is exposed to the maximum field. One can hence write:

$$
B=B_{A}+F \cdot I_{M}
$$

with $F$ the so-called Self-Field Correction Factor which depends on the cable dimensions, the arrangement of the bifilar sample, and the orientation of the applied field.

Finally, the temperature is corrected to $4.222 \mathrm{~K}$ (and to $1.900 \mathrm{~K}$ for the measurements in FRESCA performed near $1.9 \mathrm{~K})$, using:

$$
I_{C_{-} c a b}=\frac{T_{c}(B)-4.222}{T_{c}(B)-T_{b}} I_{M}
$$

\begin{tabular}{|c|c|c|c|c|c|}
\hline & $\begin{array}{l}\text { BNL } \\
\text { TB-4 }\end{array}$ & $\begin{array}{l}\text { BNL } \\
\text { TB-5 }\end{array}$ & $\begin{array}{l}\text { BNL } \\
\text { TB-6 }\end{array}$ & $\begin{array}{l}\text { BNL } \\
\text { all } 3\end{array}$ & $\begin{array}{l}\text { CERN } \\
\text { FRESCA }\end{array}$ \\
\hline No of samples & 8 & 10 & 8 & 12 & 12 \\
\hline No of tests & 14 & 20 & 12 & 46 & 26 \\
\hline \multicolumn{6}{|l|}{$\perp$-thin } \\
\hline Aver. $I_{\mathrm{C}_{\mathrm{c}} \mathrm{ab}}[\mathrm{A}]$ & 15900 & 15781 & 15845 & 15834 & 15823 \\
\hline$\sigma I_{\mathrm{C}_{-} \mathrm{cab}}[\mathrm{A}]$ & 189 & 160 & 218 & 188 & 203 \\
\hline \multicolumn{6}{|l|}{ L-thick } \\
\hline Aver. $I_{\mathrm{C}_{-} \mathrm{cab}}[\mathrm{A}]$ & 16452 & 16344 & 16566 & 16439 & 16325 \\
\hline$\sigma I_{\mathrm{C}_{\mathrm{c}} \mathrm{ab}}[\mathrm{A}]$ & 117 & 86 & 126 & 140 & 143 \\
\hline
\end{tabular}

with $T_{\mathrm{b}}$ the helium bath temperature, and $T_{\mathrm{C}}(B)$ the field dependent critical temperature given by:

$$
T_{C}(B)=9.2\left(1-\frac{B}{14.5}\right)^{0.59}
$$

or similar equation for measurements near $1.9 \mathrm{~K}$.
TABLE III

OVERVIEW OF THE VALIDATION TESTS AT BNL AND FRESCA (DATA AT $4.222 \mathrm{~K}, 7 \mathrm{~T}$ )

We measured several $U I$-curves at fields between 5-7 $\mathrm{T}$ (BNL) or 5-10 T (FRESCA) in order to obtain the $I_{\mathrm{C}-\mathrm{cab}}(B)$ relation over a relevant field range. Furthermore, at FRESCA we also measure routinely at several ramp rates (between 20 and $400 \mathrm{~A} / \mathrm{s}$ ). We designed a database structure that is equivalent for both test locations, and all raw data and measurement reports were sent daily from BNL to CERN.

\section{Validation of the Test Stations}

The measurement error in the $U I$-curve, and hence in $I_{\mathrm{C} \_c a b}$, is due to inaccuracies in voltage, current and temperature measurement. Besides these errors, the measured $I_{\mathrm{C} \_ \text {cab }}$ could depend on the soldered connections on both ends of the cable, the uniformity of the critical current of the individual strands, the current ramp rate, the positioning of the voltage taps, the sampling mounting, and temperature stratification along the cable. Several of the above given errors are difficult to quantify and we therefore decided to perform regular validation measurements on a so-called reference cable. In total 24 samples of this reference cable are used, 12 at BNL and 12 at FRESCA. These reference measurements are performed in all three test stations at BNL as well as in FRESCA. Table III presents the results of these tests, for the configurations $\perp$-thin and $\perp$-thick. The results show that the four test stations give very similar results, not only for the critical current but also for the standard deviation $\sigma$. Note also that $\sigma$ is significantly smaller for $\perp$-thick than for $\perp$-thin. The reason could be that the degradation of the thin edge along the reference cable is not uniform, or that the mounting of the cable (under a transverse pressure of 70-80 MPa) causes an additional degradation, especially present at the thin edge of the cable. Based on the results on the reference cable we have considered a total measurement accuracy of $+/-2 \%$.

\section{RESUlTS AND ANALYSIS}

\section{A. $I_{C}$ Data During Production}

All measured $I_{\text {C_cab }}$ data are presented in Figs. 3 and 4 for the 01 and 02 types of cable respectively. All the data presented here have been measured on cables that are within the dimensional specifications as given in Table I. As can be seen immediately, most $I_{\text {C_cab }}$ values are well above the minimum specification (except for one of the first cables of the 01B production). For the 


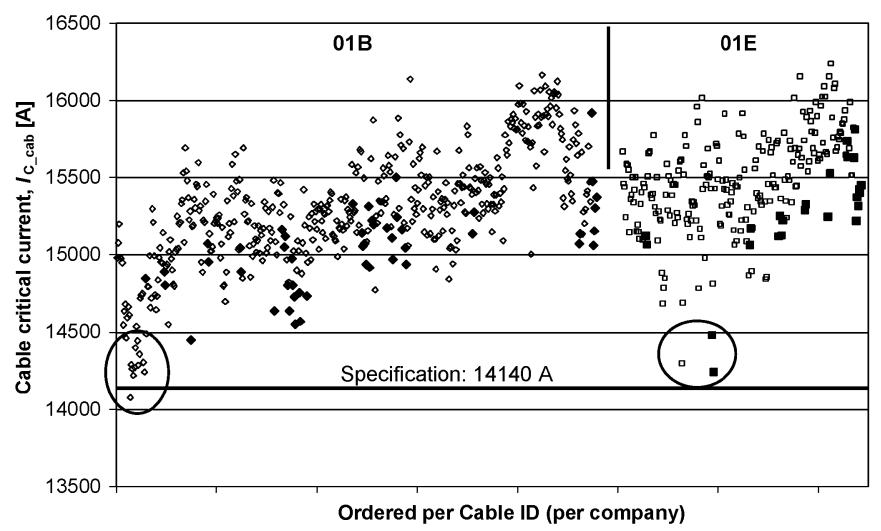

Fig. 3. Measured cable $I_{\mathrm{C}}$ values for the 01 type cables at $4.222 \mathrm{~K}, 7 \mathrm{~T}$. Open markers show the BNL data, full markers show the FRESCA results.

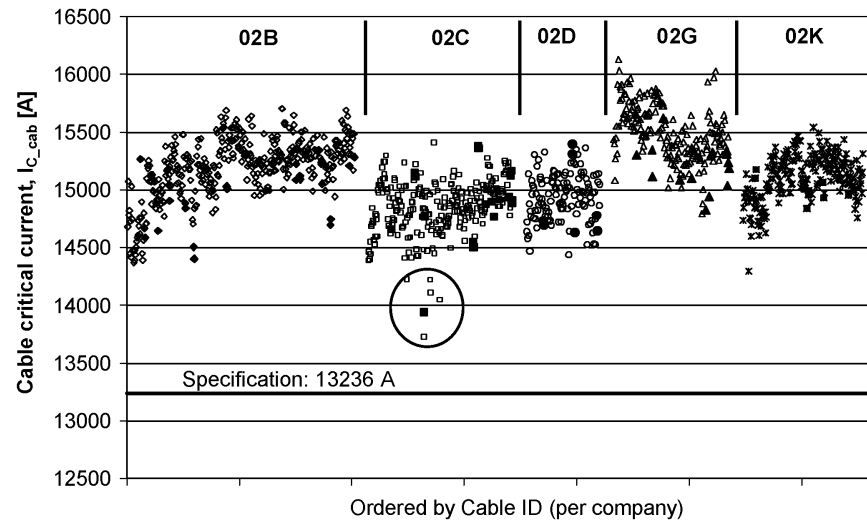

Fig. 4. Measured cable $I_{\mathrm{C}}$ values for the 02 type cables at $4.222 \mathrm{~K}, 6 \mathrm{~T}$. Open markers show the BNL data, full markers show the FRESCA results.

type 01 cables the average $I_{\text {C_cab }}$ is about $10 \%$ above the specification, for the 02 type cables it is about $12-16 \%$, depending on the manufacturer. However, some parts of the production show a relatively low critical current, see the encircled areas. After further investigation (for an example see Section IV) the origins of these reductions were found to be linked either to the strand manufacturing or the cabling process. The feedback from these measurements triggered corrective actions resulting in an increased $I_{\text {C_cab }}$ for the remaining part of the production.

\section{B. $I_{C}$ Degradation}

An important aspect in cable production is the $I_{\mathrm{C}_{-} \text {cab }}$ degradation caused by the cabling process. We define this degradation by $\left(I_{\mathrm{C}_{-} \text {cab }} / \Sigma I_{\mathrm{C}_{\text {_str }}}-1\right)$ with $\Sigma I_{\mathrm{C}_{\text {_str }}}$ the sum of the $I_{\mathrm{C} \_ \text {str }}$ values (measured at CERN) of all the strands in the cable. Since the self field distribution over the cross-section of a strand inside a cable is completely different from the self field generated by a single strand, the degradation can be either slightly positive or negative depending on the self-field correction method that is applied. More important than the absolute value of the degradation is therefore the trend of the degradation during production (for a given manufacturer) and differences (in average value and deviation) among manufacturers. The degradation data are presented in Figs. 5 and 6 for the 01 and 02 types of cable respectively. A random scatter of the points with about $\pm 2 \%$ is possible due to the accuracy in measuring $I_{\mathrm{C}_{-} \text {cab }}$ and $I_{\mathrm{C}_{-} \text {str }}$. Note

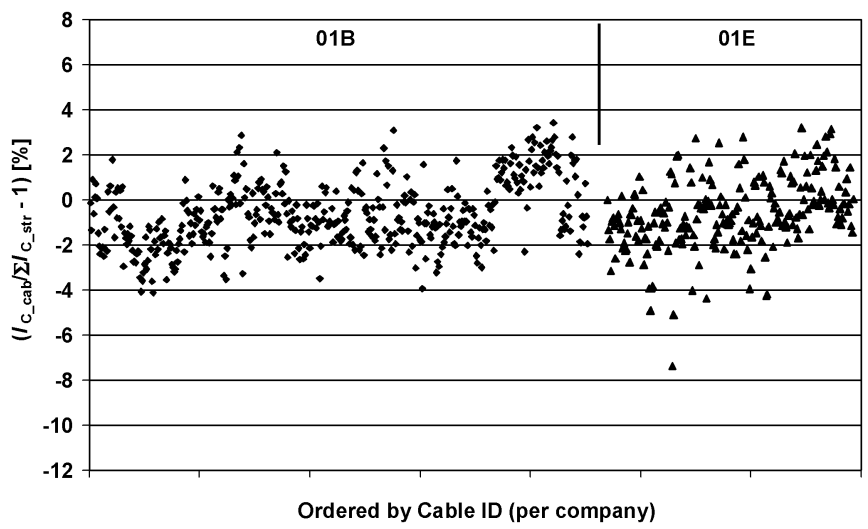

Fig. 5. Cable $I_{\mathrm{C}}$ degradation for the cables of type 01 .

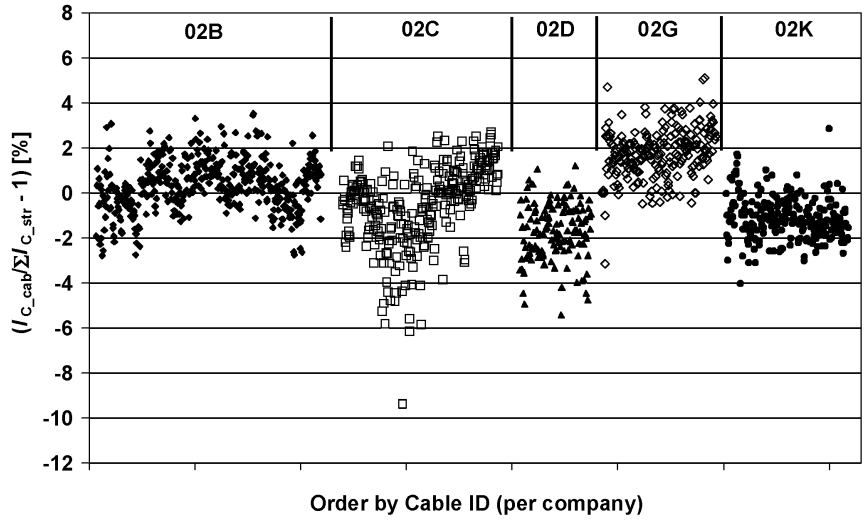

Fig. 6. Cable $I_{\mathrm{C}}$ degradation for the cables of type 02 .

also that systematic differences between the different manufacturers is entirely related to the strand and cable manufacturing since all $I_{\mathrm{C}_{-} \text {cab }}$ data are obtained with the BNL test stations having only a small systematic difference (see Section II-D), and all $I_{\text {C_str }}$ data are obtained using four CERN test stations with even smaller systematic difference [9]. One can conclude that many cables made at Brugg (01E and part of 02C) are degraded more than average, attributed to temporary problems during cabling. These problems were solved, and degradation during the rest of production came back to average. Furthermore one can see that the $02 \mathrm{G}$ and $02 \mathrm{~K}$ cables have about $3 \%$ difference in average degradation although they were both cabled at FEC. Variations in the set-up of the cabling machine in relation to the strand characteristics can therefore significantly affect the cable critical current, even for strands fulfilling the same technical specification.

During production the contractors also perform for each cabling run critical currents measurements on 5 strands before and after cabling, i.e. on virgin and extracted strands. One can define an average strand degradation over the 5 strands as $\Sigma I_{\mathrm{C}_{-} \text {extr }} / \Sigma I_{\mathrm{C} \_ \text {str }}-1$. Both $I_{\mathrm{C} \_ \text {extr }}$ and $I_{\mathrm{C} \_ \text {str }}$ are measured on the same strands and in the same test station, so that the calculated degradation does not depend on systematic errors of the test set-ups. Fig. 7 shows the correlation between this average strand degradation and the cable degradation as defined before. A positive correlation is observed, although unclear due to the measurement inaccuracy of especially the cable degradation. 


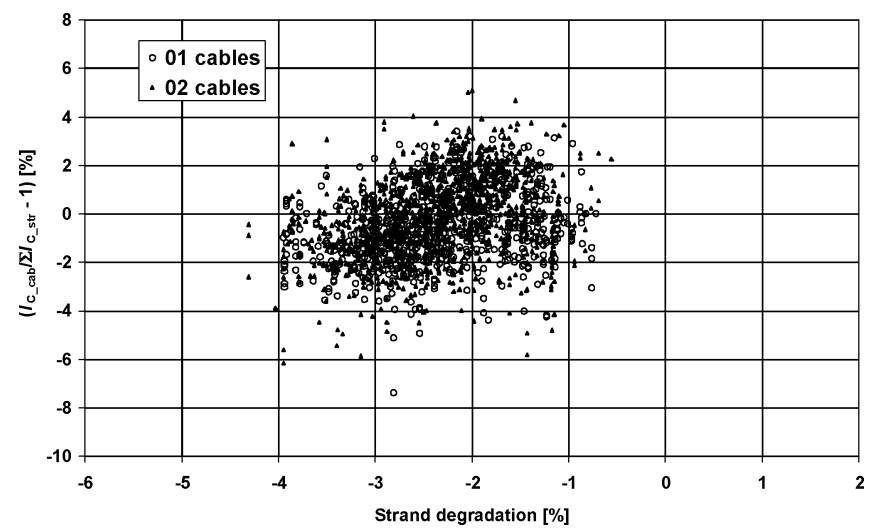

Fig. 7. Ratio between cable $I_{\mathrm{C}}$ degradation and strand degradation.

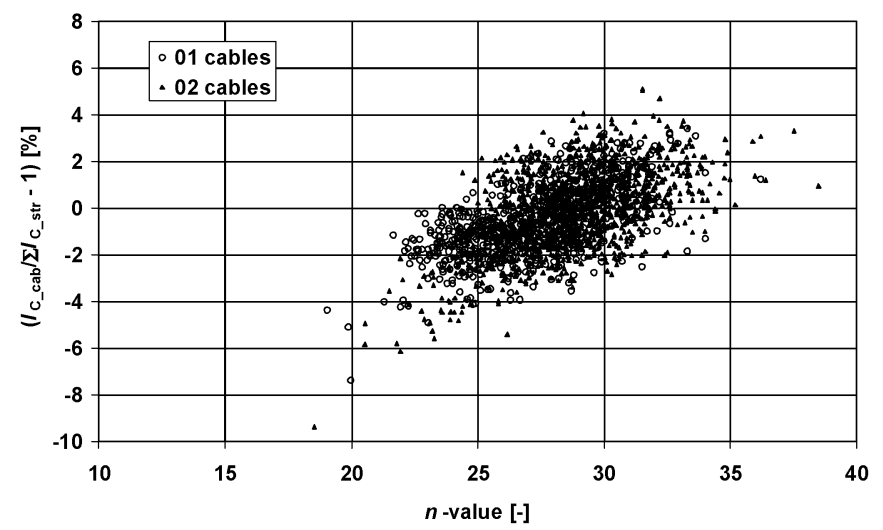

Fig. 8. Cable $I_{\mathrm{C}}$ degradation as a function of the average n-value.

A clear correlation, similar for the 01 and 02 types of cable, is observed between the degradation and the $n$-value, see Fig. 8 . The $n$-value of a cable is calculated as the average $n$-value deduced from all $U I$-curves at BNL between 6 and $7 \mathrm{~T}$ measured on that cable. A high $n$-value, close to the $n$-value of a single strand, usually indicates that all strands in the cable have very similar $I_{\mathrm{C}-s t r}$. Low $n$-value can indicate that one or more strands have a (locally) degraded critical current, or that the joint with the current lead is non-uniform. The origin of the degradation can be found by investigating $I_{\text {C_cab }}$ and $n$ deduced from $U I$-measurements performed at various ramp rates [10], or by performing $I_{\mathrm{C}_{-} \text {str }}$ measurements on extracted strands (see Section IV).

\section{Cable as Compared to Extracted Strands}

Testing of entire cables, requiring a high current power supply and a large background magnet, is usually complicated and expensive. As an alternative it could suffice to perform $I_{\mathrm{C}}$ measurements on a small subset of strands extracted from the cable. On a certain number of cables during the LHC production $I_{\mathrm{C}}$ measurements have been performed on the cable $\left(I_{\mathrm{C} \_c a b}\right)$ as well as on five extracted strands per cable $\left(I_{\mathrm{C} \_ \text {extr }}\right)$. The ratio between $I_{\mathrm{C} \_c a b}$ and $\left(N_{\mathrm{S}} / 5\right) \Sigma I_{\mathrm{C} \_ \text {extr }}$ is shown in Figs. 9 and 10. All strand data are measured in the CERN test stations, hence eliminating systematic differences between the cables from the 6 contractors. Both figures show that the average ratio is about 1.02 , implying that the self field correction factor is slightly too large. An important conclusion is that cable and extracted strand show very similar $I_{\mathrm{C}}$ results (taking into account the measurement errors). Replacing one type of measurement by the other is

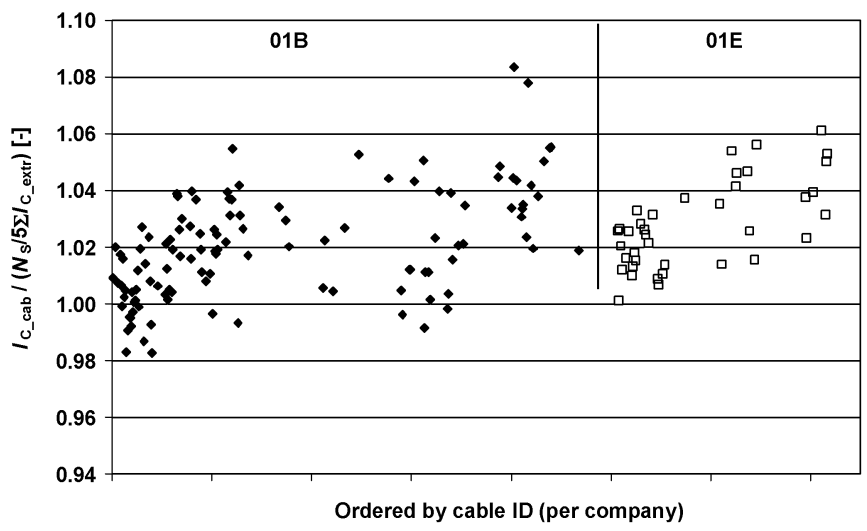

Fig. 9. Ratio between $I_{\mathrm{C}_{-} \text {cab }}$ and extracted strand $I_{\mathrm{C}}$ for the cables of type 01 .

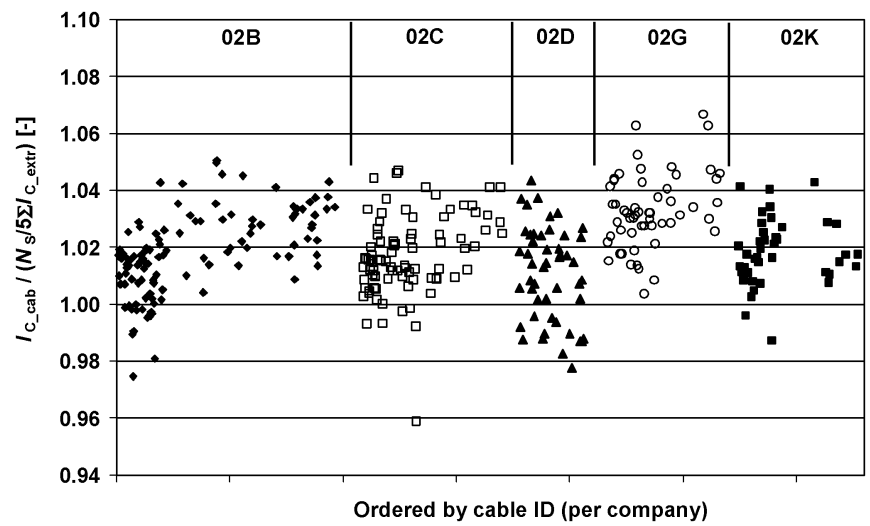

Fig. 10. Ratio between $I_{\mathrm{C}-\text { cab }}$ and extracted strand $I_{\mathrm{C}}$ for the cables of type 02 .

therefore possible, at least if the margin to the minimum specification current is large (see Figs. 3 and 4), and the variation in the strand critical current is small (as is the case for the LHC wires, where $I_{\text {C_str }}$ is kept within $\pm 4 \%$ from the average). However, one should always take into account that local strand defects are not always detected using extracted strand measurements, unless of course all strands of the cable are tested. Because of the large $I_{\mathrm{C}}$ margin of the cables, that was observed for a substantial fraction of the production, it was decided not to extend the cable $I_{\mathrm{C}}$ measurements at BNL after spring 2005 (see also Fig. 1) but instead to rely on extracted strand measurements with additional cable measurements at FRESCA in case of suspicious results.

\section{D. $1.9 \mathrm{~K}$ Versus $4.222 \mathrm{~K}$ Correlation}

All $I_{\text {C_cab }}$ measurements in FRESCA have been performed at 1.9 and $4.3 \mathrm{~K}$. The ratio $R_{\text {cab }}$ between the critical currents at both temperatures is shown in Figs. 11 and 12. The solid lines in the graphs show the average ratio $R_{\mathrm{str}}$ as measured on the virgin strands for each cable manufacturer. The extremely good correlation between $R_{\mathrm{cab}}$ and $R_{\mathrm{str}}$ indicates that cable $I_{\mathrm{C}}$ testing can be done at $4.3 \mathrm{~K}$ only and that the $1.9 \mathrm{~K}$ results can be obtained through $1.9 \mathrm{~K}$ testing on single strands. This is not surprising, since the effect of temperature on $I_{\mathrm{C}}$ is governed by the $\mathrm{Nb}$-Ti properties, which are not significantly affected by the cabling process.

\section{Anomalies During Production}

As mentioned in Section II, the electrical characteristics of the cables (in terms of $I_{\mathrm{C} \_c a b}, n$, and degradation) were mon- 


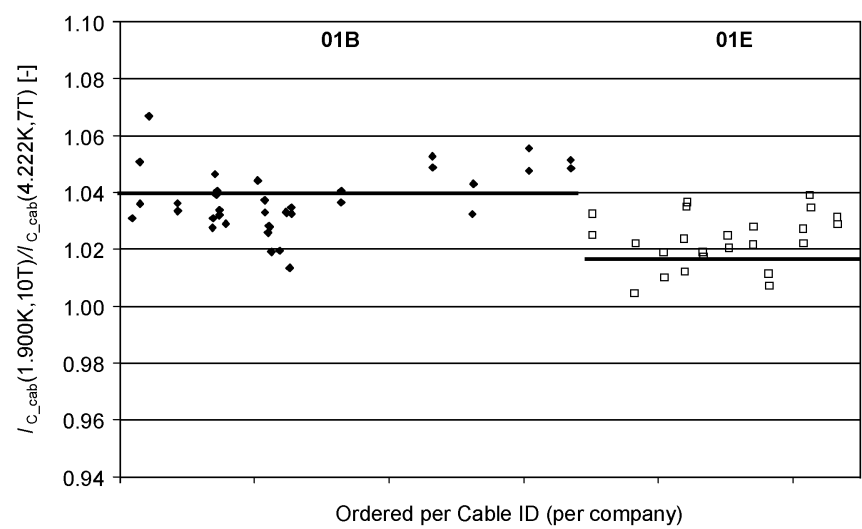

Fig. 11. Ratio between cable $I_{\mathrm{C}}$ at $1.9 \mathrm{~K}(10 \mathrm{~T})$ and at $4.222 \mathrm{~K}(7 \mathrm{~T})$ for the cables of type 01 .

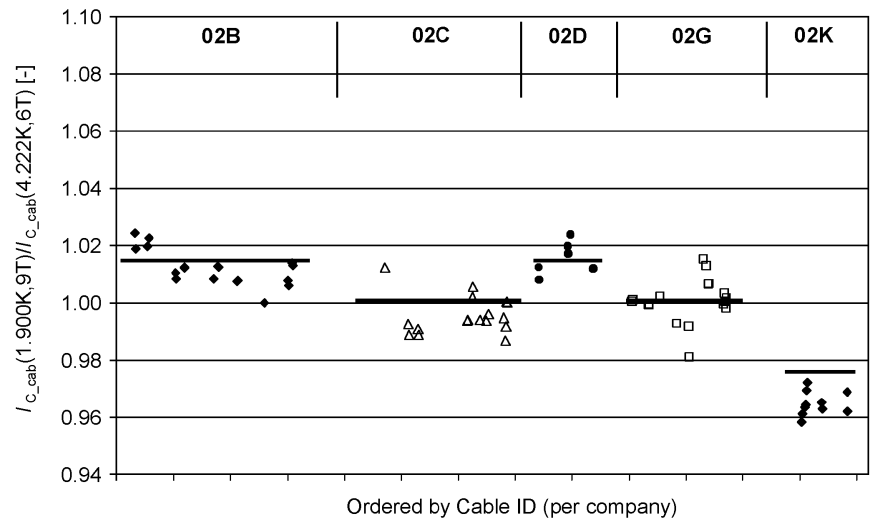

Fig. 12. Ratio between cable $I_{\mathrm{C}}$ at $1.9 \mathrm{~K}(9 \mathrm{~T})$ and at $4.222 \mathrm{~K}(6 \mathrm{~T})$ for the cables of type 02 . The $02 \mathrm{~B}$ production cables at FEC is not included.

itored during production, and anomalous behavior was investigated in more detail. As an example we show here the low $I_{\text {C_cab }}$ value with corresponding high degradation $(-9.3 \%$, see Fig. 6) and low $n$ (18, see Fig. 8), measured at BNL. An additional test at FRESCA confirmed these values, also at $1.9 \mathrm{~K}$, indicating that the degradation was not caused by sample preparation, mounting, and testing. Tests at various ramp rates were then performed at FRESCA at $1.9 \mathrm{~K}, 9 \mathrm{~T}$, see Fig. 13. The results at the $\perp$-thick configuration show a high $n$-value, similar to that of a virgin strand, and no dependency of $I_{\mathrm{C}_{-} \text {cab }}$ and $n$ on the ramp rate, demonstrating normal and uniform strand quality at the thick edge of the cable. The low $n$-value and ramp-rate dependence of $I_{\mathrm{C}_{-} \text {cab }}$ at the $\perp$-thin configuration indicate that one or more strands on the thin edge of the cable have a more than usual strand degradation. This conclusion was confirmed by testing the 36 strands after extracting them from the cable, see Fig. 14. We observed clearly that several strands had significantly lower $I_{\mathrm{C} \_s t r}$ and corresponding low $n$-value.

Above effects had to be caused by a non-optimized set-up of the cabling machine (even though the cable dimensions were still within specification), because the virgin strands had uniform critical current. This cable has $I_{\text {C_cab }}=13726 \mathrm{~A}$, while $\Sigma I_{\text {C_extr }}=14313 \mathrm{~A}$, so $I_{\text {C_cab }} / \Sigma I_{\text {C_extr }}=0.96$ (see also the lowest point in Fig. 9). For this cable, extracted strand tests significantly overestimated the critical current of the cable.

Another anomaly became visible while testing the $02 \mathrm{~K}$ cables in $\perp$-thin and $\perp$-thick directions. Usually the $\perp$-thick ori-

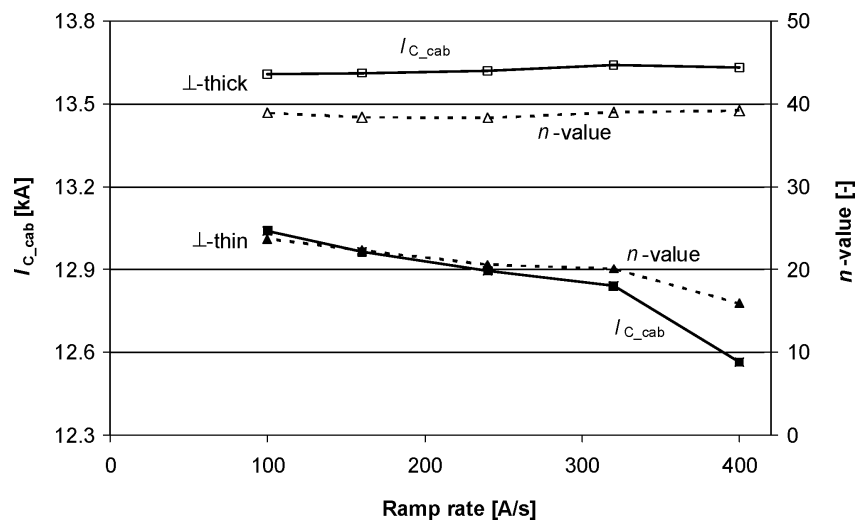

Fig. 13. Cable critical current (full line) and $n$-value (dotted line) at $1.900 \mathrm{~K}$, $9 \mathrm{~T}$ in $\perp$-thin (full markers) and $\perp$-thick (open markers) configuration.

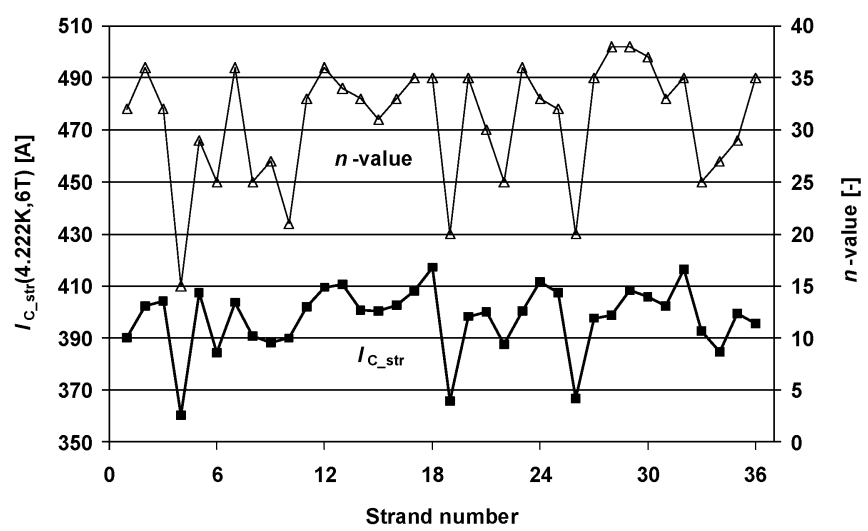

Fig. 14. Strand $I_{\mathrm{C}}$ (full markers) and $n$-value (open markers) for the $36 \mathrm{ex}$ tracted strand coming from a cable with strongly degraded cables $I_{\mathrm{C}}$.

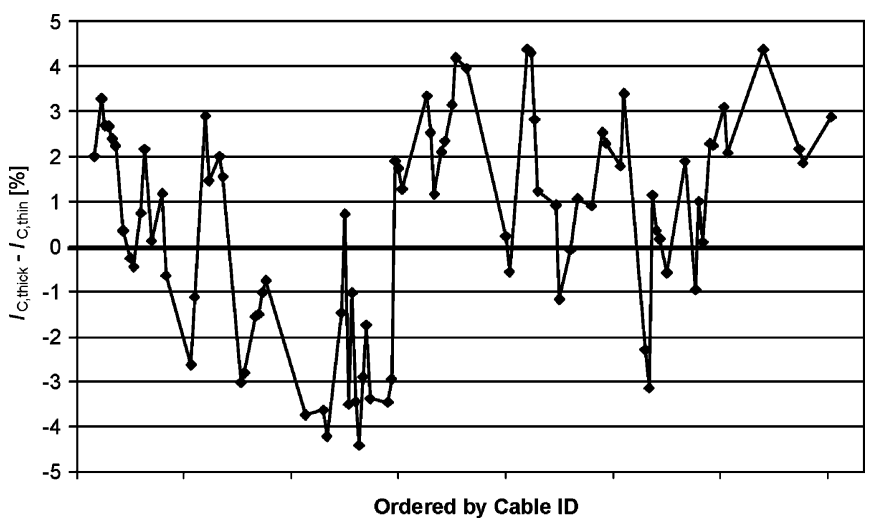

Fig. 15. Ratio between $I_{\mathrm{C}_{-} \text {cab }}$ measured under $\perp$-thick and $\perp$-thin orientation.

entation gives an $I_{\mathrm{C} \_c a b}$ value which is a few percent larger than the $\perp$-thin orientation, mainly because the strands are compacted more at the thin edge than at the thick edge. The average $I_{\mathrm{C} \_c a b}$ difference (between the two field orientations) over the entire LHC production is 3\% (with $\sigma=1.6 \%$ ). However, during the $02 \mathrm{~K}$ production this difference became negative (see Fig. 15), apparently correlated to the set-up of the cabling machine, which was tuned to optimize the dimensional characteristics of the cable [11]. After feed-back to FEC, the set-up was adjusted differently and the $I_{\mathrm{C}}$-degradation at the thin edge became consistent with the cables of the other contractors. The details of these adjustments were not communicated to CERN. 


\section{CONCLUSION}

During the production of the LHC Nb-Ti superconducting cables for the main dipole and quadrupole magnets an unprecedented number of cable critical current measurements were performed. During the seven years of production in total 2131 tests were performed on 10 different types of cable. The majority of these tests were made at BNL at $4.3 \mathrm{~K}$, whereas additional tests have been performed in the cable test facility FRESCA at CERN, both at $4.3 \mathrm{~K}$ and at $1.9 \mathrm{~K}$.

Regular qualification tests on a reference cable show that the four tests stations have a systematic difference less than $0.5 \%$, but a random accuracy of about $\pm 2 \%$, mainly due to variations in sample preparation and soldering to the current leads.

We conclude that almost all cables showed a critical current about $8 \%-16 \%$ above the minimum specified value, hence guarantying a very high critical current for all cables delivered to the magnet assemblers. By following the trends in $I_{\mathrm{C} \_c a b}, n$-value, and degradation (both on the thin and thick edge of the cable) we were able to detect anomalies in production. After feedback to the companies, corrective actions were taken resulting in more uniform critical current values.

A clear correlation exists between the $n$-value and the degradation. Performing $U I$-measurements for various ramp rates (in order to obtain the ramp rate dependence of $I_{\mathrm{C}_{-} \text {cab }}$ and $n$ ) turned out to be a useful tool for understanding possible defects in a cable.

We observed a very good correlation between the cable critical current and the weighted sum of the critical currents of five extracted strands. A systematic difference of about $2 \%$ is observed, caused by the self-field correction method applied when calculating the cable critical current. It is important to note that for cables having non-uniform strands (or strands with local defects) extracted strand tests always overestimate $I_{\mathrm{C}}$ (as evidenced in Section IV) as compared to the cable critical current. This effect primarily comes from the different voltage pattern along an extracted strand as compared to the cables, and increases with increasing compaction at the edges and with increasing $I_{\mathrm{C}}$ non-uniformity among the strands.

For the last part of the LHC cable production we replaced cable $I_{\mathrm{C}}$ measurements by extracted strand measurements (on a small subset of strands). This was feasible because of the uniform and high critical current attained during the production (showing a high margin relative to the specified critical current), and also because of the stringent quality control on the virgin strands, reducing to a minimum the possibility of having local strand defects.

The correlation between the critical current at $1.9 \mathrm{~K}$ and $4.222 \mathrm{~K}$ is the same for virgin strands and for the cable. We did not come upon one cable sample that showed an inconsistent behavior between the $1.9 \mathrm{~K}$ and $4.222 \mathrm{~K}$ result. This is not surprising, since the effect of temperature on $I_{\mathrm{C}}$ is governed by the Nb-Ti properties, which are not significantly affected by the cabling process.

\section{ACKNOWLEDGMENT}

The authors thank all people that have been involved in cable sample preparation, testing, analysis, and data base organization, both at BNL and at CERN.

\section{REFERENCES}

[1] The LHC Study Group, The Large Hadron Collider Design Report vol. I, CERN-2004-003, June 4, 2004.

[2] J. D. Adam, T. Boutboul, G. Cavallari, Z. Charifoulline, C.-H. Denarie, S. Le Naour, D. F. Leroy, L. R. Oberli, D. Richter, A. P. Verweij, and R. Wolf, "Status of the LHC superconducting cable mass production," IEEE Trans. Appl. SC., vol. 12, no. 1, pp. 1056-1062, 2002.

[3] D. Leroy, "Review of the R\&D and supply of the LHC superconducting cables," IEEE Trans. Appl. SC., vol. 16, pp. 1152-1159, 2006.

[4] A. P. Verweij, J. Genest, A. Knezovic, D. F. Leroy, J.-P. Marzolf, and L. R. Oberli, " $1.9 \mathrm{~K}$ test facility for the reception of the superconducting cables for the LHC," IEEE Trans. Appl. SC., vol. 9, pp. 153-156, 1999.

[5] G. Prodell and A. Arn, "A facility for evaluating superconductors above atmospheric pressure at $1.8 \mathrm{~K}$," Adv. in Cryog. Eng., vol. 43, pp. 443-450, 1998, P. Kittle, Ed.

[6] R. Thomas, A. Ghosh, D. McChesney, and A. Jain, "Testing and evaluation of superconducting cables for the LHC," in Proc. 1999 Particle Accl. Conf., New York, 1999, pp. 3188-3190.

[7] D. Leroy, G. Spigo, and A. P. Verweij, "Design and manufacture of a large-bore $10 \mathrm{~T}$ superconducting dipole for the CERN cable test facility," IEEE Trans Appl. SC, vol. 10, pp. 178-182, 2000.

[8] T. Boutboul, P. Lezza, and R. Wolf, Low-Current Resistance of Multifilamentary Superconducting $\mathrm{Cu} / \mathrm{NbTi}$ Strands LHC Project Note 312, 2003.

[9] T. Boutboul et al., Critical Current Test Facilities for LHC Superconducting NbTi Cable Strands LHC Project Report 520, 2001.

[10] A. P. Verweij, The Consequence of Self-Field and Non-Uniform Current Distribution on Short Sample Tests of Superconducting Cables LHC Project Report 151, 1997.

[11] T. Shimada et al., "Manufacturing of superconducting cable for the LHC-Key technology and statistical analysis," IEEE Trans. Appl. SC, vol. 12, pp. 1075-1078, 2002. 